\title{
Dissociation of Carboxyl-Terminated Cascade Polymers: Comparison with Theory
}

\author{
H. Zhang and P. L. Dubin* \\ Department of Chemistry, Indiana University-Purdue University, Indianapolis, Indiana 46202
}

\author{
J. Kaplan \\ Department of Physics, Indiana University-Purdue University, Indianapolis, Indiana 46202
}

\author{
C. N. Moorefield and G. R. Newkome \\ Department of Chemistry, University of South Florida, Tampa, Florida 33620
}

Received: September 25, $1996^{\otimes}$

\begin{abstract}
The dissociation of carboxyl-terminated cascade polymers (generations $1-4$ ) in $0.10 \mathrm{M} \mathrm{NaCl}$ has been studied by potentiometric titration. Experimental surface potentials were compared to the theoretical values calculated from the nonlinearized Poisson-Boltzmann equation. Experimental values are smaller than those predicted by theory for generations $2-4$ in $\mathrm{NaCl}$. The lower experimental potential is attributed in part to the effect of counterion binding, which is supported by the fact that significantly larger surface potentials are observed when $\mathrm{Na}^{+}$is replaced by tetramethylammonium ion $\left(\mathrm{TMA}^{+}\right)$. Potentials higher than those predicted by theory were observed at high degree of dissociation for generations 3 and 4 in TMACl, which may be due to the effect of the high surface charge density of cascade polymers on the local dielectric constant.
\end{abstract}

\section{Introduction}

The electrostatic properties of colloids are generally described in terms of the surface potential and surface charge density, $\psi_{\mathrm{o}}$ and $\sigma$, respectively. The relationship between $\psi_{\mathrm{o}}$ and $\sigma$ is arrived at via the Poisson-Boltzmann equation $(\mathrm{P}-\mathrm{B}) ;{ }^{1-3}$ however, experimental demonstration of the theory with colloid particles is still the subject of investigation. ${ }^{3,4}$ For polymers and colloids with titratable ionophores, potentiometric titration provides a direct test of electrostatic theory. Thus, $\mathrm{pH}$ titration has been extensively used to evaluate the surface potential of proteins, ${ }^{5-8}$ synthetic polyacids ${ }^{3,9-14}$ and micelles; ${ }^{15,16}$ however, all these systems exhibit complicating factors. Proteins have many different types of titratable groups, and some of them are indistinguishable by $\mathrm{pH}$ titration. Conformational changes that occur with the dissociation of some polyacids strongly affect their titration behavior. ${ }^{11,17,18}$ Although the analysis of titration data for micelles appears to be straightforward in some cases, ${ }^{15}$ changes in micelle size with ionization ${ }^{16}$ also affect the dissociation behavior.

Titratable latexes have been used as models of symmetric spherical colloids. The results obtained from these systems may not, however, be applicable to many other colloidal systems for several reasons: First, latex diameters are typically 40$400 \mathrm{~nm}$, much bigger than those encountered with other colloid systems such as micelles and proteins, which generally lie in the range of 3-20 nm diameter. This dimensional difference may have a strong influence on electrostatic properties because of surface curvature effects. Second, titrations of latex commonly reveal fewer titratable acid groups than the amount of acid comonomer used in synthesis, suggesting that some fraction of these groups are buried in the particle interior. Consequently, reported charge densities are often not repeatable, even when the latex particles are prepared by identical recipes. ${ }^{19}$ Last, latex particles tend to aggregate at low charge density.

In order to evaluate theoretical treatments of the electrostatic behavior of small charged spherical solutes, one seeks compact,

${ }^{\otimes}$ Abstract published in Advance ACS Abstracts, April 1, 1997. hydrophilic, uniformly charged particles. Cascade polymers are densely branched dendritic spherical macromolecules, continuing radial layers that originate from a multifunctional core. The distal functional groups can be synthetically varied. Carboxylterminated cascade polymers have been successfully synthesized and structurally characterized. ${ }^{20-22}$ The surface charge density of these polymers can be readily manipulated via the $\mathrm{pH}$. Although the size may change to some extent with $\mathrm{pH}$ due to increasing electrostatic repulsion among surface groups with increase of degree of dissociation $\alpha$, all the carboxylic groups are exposed and thus susceptible to reaction with base, and the conformation and shape are retained. Besides allowing variation of the colloid surface charge density, these well-defined spherical compounds also facilitate an examination of the effect of surface group compactness (surface area per headgroup) on the dissociation of carboxylic groups. Hence, these materials may be considered as good small spherical model colloids.

The present work focuses on the characterization by potentiometric titration of the dissociation of carboxyl-terminated cascade polymers. The relationship among surface potential, dendrimer structure, and ionization degree is obtained. These results are compared with calculated values produced by solving the Poisson-Boltzmann equation for a smeared-charged sphere.

\section{Methods}

Materials. Carboxylic terminated cascade polymers ( $Z$ cascade:methane[4]:(3-oxo-6-oxa-2-azaheptylidyne):(3-oxo-2azaheptylidyne):propanoic acids) were made by iterative stepwise synthesis. The method ${ }^{22}$ is comprised of amide formation between the tetraacid $\mathbf{1}$ and the amine $\mathbf{2}$ via treatment with 1-hydroxybenzotriazole and dicyclohexylcarbodiimide in $\mathrm{N}, \mathrm{N}$ dimethylformamide at $25^{\circ} \mathrm{C}$, giving a dodecaester $\mathbf{3}$, which was hydrolyzed using $95 \%$ formic acid at $25{ }^{\circ} \mathrm{C}$ to give the dodecaacid 4 generation 1 (as seen in Scheme 1). Higher generations were prepared by repetition of this two-step sequence. The acids were purified by dialysis (Spectra Por 6 dialysis membrane (MWCO 1000), followed by reverse-phase 


\section{SCHEME 1: Synthesis Route of Carboxyl-Terminated} Cascade Polymers
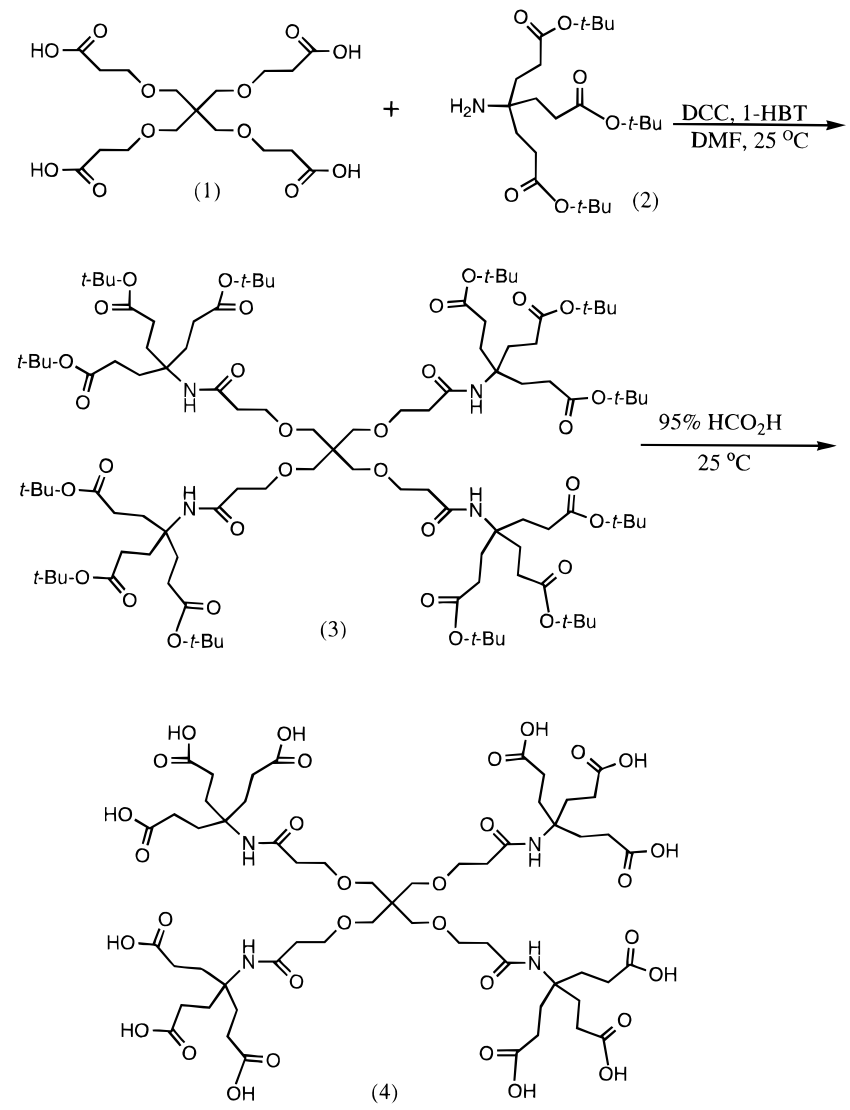

TABLE 1: Characteristics of Carboxyl-Terminated Cascade Polymers

\begin{tabular}{ccr}
\hline generation number & no. of terminal $\mathrm{COOH}$ & MW \\
\hline 1 & 12 & 1341 \\
2 & 36 & 4092 \\
3 & 108 & 12345 \\
4 & 324 & 37102
\end{tabular}

HPLC (ODS: $\mathrm{H}_{2} \mathrm{O} / \mathrm{CH}_{3} \mathrm{CN}(60: 40)$ ). Detailed information can be found elsewhere. ${ }^{22}$ Table 1 shows the characteristics of cascade polymers generations $1-4(\mathrm{G} 1-\mathrm{G} 4)$.

Standard $\mathrm{NaOH}(0.100 \mathrm{~N})$ and $\mathrm{HCl}(0.100 \mathrm{~N})$ solutions and analytical grade $\mathrm{NaCl}$ were from Fisher Scientific (Pittsburgh, PA). Tetramethylammonium chloride (TMACl, purity $\geq 97 \%$ ) and tetramethylammonium hydroxide (TMAH, purity $\geq 97 \%$ ) were from Aldrich Chem. (Milwaukee, WI). Milli-Q-water was used throughout this work.

Quasi-Elastic Light Scattering. Mean apparent Stokes radii were determined in $0.10 \mathrm{M} \mathrm{NaCl}$ at $25 \pm 1{ }^{\circ} \mathrm{C}$ with a DynaPro801 (Protein Solutions Inc., Charlottesville, VA.), which employs a $30 \mathrm{~mW}$ solid-state 780-nm laser and an avalanche photodiode detector. Samples prepared in $0.10 \mathrm{M} \mathrm{NaCl}$ at different $\mathrm{pH}$ were introduced into the $7-\mu \mathrm{L}$ cell via $0.1-\mu \mathrm{m}$ Anotec filters. The $90^{\circ}$ scattering data were analyzed via the method of cumulants. Apparent hydrodynamic radii $\left(R_{\mathrm{h}}\right)$ were calculated from diffusion coefficients assuming that interparticle interactions in $0.10 \mathrm{M} \mathrm{NaCl}$ are negligible.

Potentiometric Titration. $\mathrm{pH}$ titrations were conducted with a Beckman $\Phi 34 \mathrm{pH}$ meter equipped with a combination electrode under nitrogen atmosphere at $24 \pm 1{ }^{\circ} \mathrm{C}$. Solutions of $0.10 \mathrm{M}$ $\mathrm{NaCl}$ or $\mathrm{TMACl}$ with or without cascade polymer were first adjusted to $\mathrm{pH}=2.00$ then titrated with $0.100 \mathrm{~N} \mathrm{NaOH}$ or TMAH solution.
Calculations. The relationship between the apparent dissociation constant $K_{\mathrm{a}}$ and the degree of ionization $\alpha$ of the carboxylic groups of a polyacid is described as

$$
\mathrm{p} K_{\mathrm{a}}=\mathrm{pH}+\log (1-\alpha) / \alpha
$$

where $\alpha$ is defined as

$$
\alpha=\left[-\mathrm{COO}^{-}\right] /\left([\mathrm{COOH}]+\left[-\mathrm{COO}^{-}\right]\right)
$$

The $\mathrm{pH}$ of a polyacid solution can be generally described by ${ }^{23,24}$

$$
\mathrm{pH}=\mathrm{p} K_{0}-\log (1-\alpha) / \alpha+0.434\left(\mathrm{~d} G_{\mathrm{el}} / \mathrm{d} \alpha\right) / R T
$$

where $\mathrm{p} K_{\mathrm{o}}$, the intrinsic dissociation constant, is obtained by extrapolating $\mathrm{p} K_{\mathrm{a}}$ to $\alpha=0$, and $\left(\mathrm{d} G_{\mathrm{el}} / \mathrm{d} \alpha\right)$ is the electrostatic Gibbs free energy change per unit degree of dissociation. Combination of eqs 1 and 3 leads to

$$
\mathrm{p} K_{\mathrm{a}}-\mathrm{p} K_{\mathrm{o}}=0.434\left(\mathrm{~d} G_{\mathrm{el}} / \mathrm{d} \alpha\right) / R T
$$

The right hand side of eq 4 may be related to the surface potential by

$$
\mathrm{d} G_{\mathrm{el}} / \mathrm{d} \alpha=-\mathrm{e} N_{\mathrm{a}} \psi_{\mathrm{o}}(\alpha)
$$

where $e$ is the elemental electric charge and $N_{\mathrm{a}}$ Avogaro's number. Combining eqs 4 and 5 ,

$$
\mathrm{p} K_{\mathrm{a}}-\mathrm{p} K_{\mathrm{o}}=0.434 \mathrm{e} \psi_{\mathrm{o}}(\alpha) / k T
$$

Thus, the surface potential $\psi_{\mathrm{o}}(\alpha)$, at the site where $\mathrm{H}^{+}$ originates, can be experimentally obtained via eq 6 . For uniformly charged spheres, the potential $(\psi)$ at a distance $r$ from the center in a symmetrical 1:1 electrolyte can be calculated via the Poisson-Boltzmann equation:

$$
\frac{d}{r^{2} \mathrm{~d} r}\left(r^{2} \frac{\mathrm{d} \psi}{\mathrm{d} r}\right)=\frac{8 \pi \mathrm{e} n}{\epsilon} \sinh \frac{\mathrm{e} \psi}{k T}
$$

where $n$ is the electrolyte concentration, $\epsilon$ the dielectric constant here set at 78.5, and $k$ the Boltzmann constant.

Numerical solutions of the nonlinearized $\mathrm{P}-\mathrm{B}$ equation were made with the computer program Mathematica 2.2. In solving the $\mathrm{P}-\mathrm{B}$ equation, the apparent geometric surface charge density $\sigma_{\mathrm{g}}$, needed to determine the boundary condition $\mathrm{d} \psi / \mathrm{d} r(=$ $-4 \pi \sigma / \epsilon)$, is taken as e $N_{\text {app }} / 4 \pi a^{2}$, where $a$ is the radius, $N_{\text {app }}=$ $N_{\mathrm{t}} \alpha$ is the apparent charge number, and $N_{\mathrm{t}}$ is the number of total ionizable groups on the cascade polymer. In the present study, hydrodynamic radii measured by quasi-elastic light scattering (QELS) as a function of $\mathrm{pH}$ were used as the distance from the center of cascade polymer to the dissociation position. For G1, the radius of $1.2 \mathrm{~nm}$ from size exclusion chromatography (SEC) measurement ${ }^{22}$ was used because of the weak scattering of the sample.

\section{Results and Discussion}

The sizes of G2-G4 measured by QELS are shown in Figure 1. The results show that there is some expansion with increase of the degree of ionization. This may be attributed to the increasing electrostatic repulsive force among ionized groups when $\alpha$ increases. Values for $r$ in eq 7 were taken from the QELS results.

The dependence of $\mathrm{p} K_{\mathrm{a}}$ on $\alpha$ in $0.10 \mathrm{M} \mathrm{NaCl}$ for cascade polymers $\mathrm{G} 1-\mathrm{G} 4$ is shown in Figure 2. Several features are observed. First, $\mathrm{p} K_{\mathrm{o}}=4.4 \pm 0.13$ is smaller than that of a comparable monomeric acid, e.g., propionic acid, $\mathrm{p} K=4.87$. 


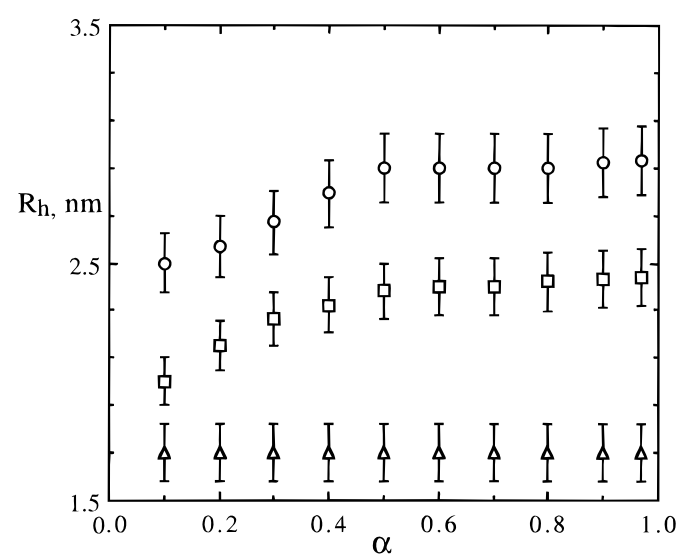

Figure 1. Dependence of hydrodynamic radius of cascade polymers on degree of ionization in $0.10 \mathrm{M} \mathrm{NaCl}$ : G2 $(\triangle), \mathrm{G} 3(\square)$, and G4 $(\bigcirc)$.

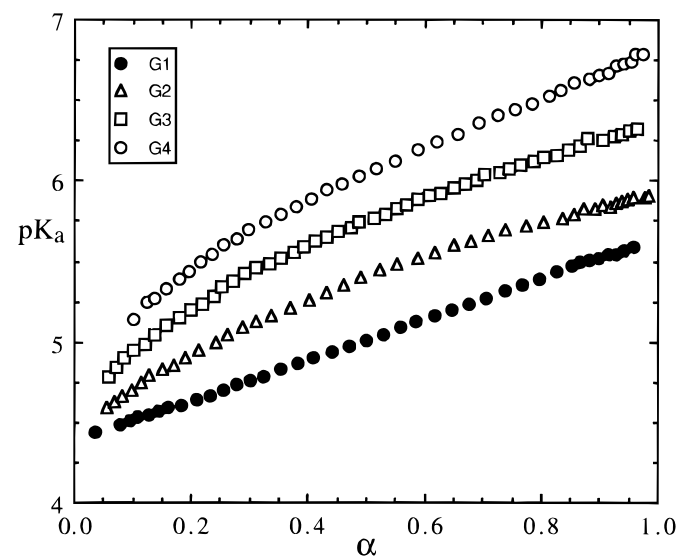

Figure 2. Relationship between $\mathrm{p} K_{\mathrm{a}}$ and $\alpha$ for cascade polymers in $0.10 \mathrm{M} \mathrm{NaCl}$

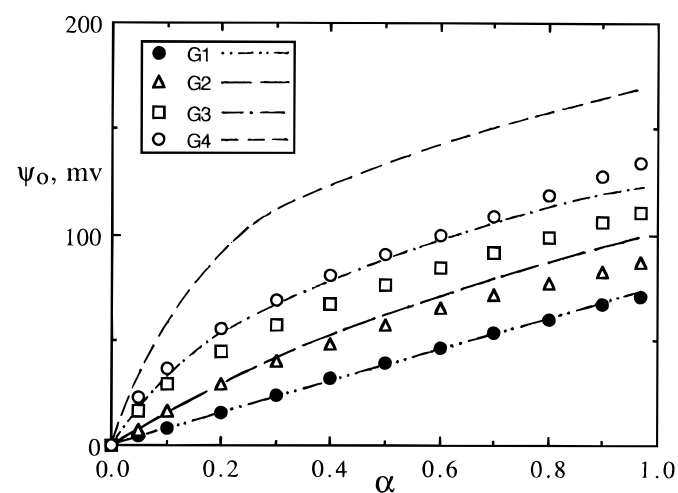

Figure 3. Surface potentials (absolute values) of cascade polymers in $0.10 \mathrm{M} \mathrm{NaCl}$ : experimental (symbols), theoretical (broken lines).

Second, $\mathrm{p} K_{\mathrm{a}}-\mathrm{p} K_{\mathrm{o}}$ increases with generation number, which may be attributed to the increase of the electrostatic repulsive interaction among the more densely packed ionized groups of the higher generations. Finally, progressive departure from linearity is observed with increasing generation number.

Comparison with Theory. The linearized $\mathrm{P}-\mathrm{B}$ equation was found to be valid only for the lowest generation, G1, and only when $\alpha<0.1$. Calculated values of $\psi_{\mathrm{o}}$ using the nonlinearized $\mathrm{P}-\mathrm{B}$ equation are compared in Figure 3 to experimental results. For G1, the dependence of the potential on $\alpha$ is almost linear, and the agreement between experiment and theory is excellent. For all other generations, theoretical values of $\psi_{\mathrm{o}}$ exceed the experimental ones, with larger deviation for higher generations. For generation 2, experiment and theory agree at $\alpha<0.3$, but then progressively diverge. For G3 and

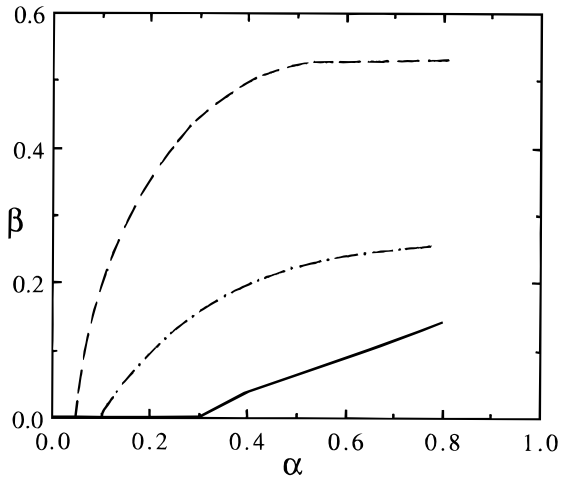

Figure 4. Derived degree of counterion binding for cascade polymers in $0.10 \mathrm{M} \mathrm{NaCl}$ : G2 (-), G3 (-•-), and G4 (- -).

TABLE 2: Critical Conditions for Counterion Binding in $0.10 \mathrm{M}$ NaCl

\begin{tabular}{cccc}
\hline generation no. & radius $(\AA)$ & $\alpha_{\mathrm{c}}$ & $\sigma_{\mathrm{c}}\left(\mathrm{C} / \mathrm{m}^{-2}\right)$ \\
\hline 2 & 17 & 0.31 & 0.049 \\
3 & 20 & 0.10 & 0.034 \\
4 & 25 & 0.05 & 0.033
\end{tabular}

G4, deviations start at lower $\alpha$, but are basically independent of $\alpha$ at moderate or large $\alpha$.

There are several possible explanations for the depression of $\psi_{\mathrm{o}}(\alpha)$ relative to calculated values. Counterion binding will lead to an $N_{\text {eff }}$ smaller than $N_{\text {app }}$, thus reducing $\sigma_{\text {eff. }}$ On the basis of many reports, ${ }^{12,14,18}$ it is deduced that counterion binding affects the dissociation of a polyacid, especially at high $\alpha$. Thus, deviations in present systems may be attributed at least in part to the effect of counterion binding.

If the $\mathrm{P}-\mathrm{B}$ equation is solved using the experimental $\psi_{\mathrm{o}}(\alpha)$, the effective surface charge density, $\sigma_{\text {eff }}\left(\sigma_{\text {eff }}=\sigma_{\mathrm{g}}(1-\beta)\right)$, can be obtained, where $\beta=\left(\sigma_{\mathrm{g}}-\sigma_{\mathrm{eff}}\right) / \sigma_{\mathrm{g}}$ is the degree of counterion binding. The dependence of $\beta$ on $\alpha$ obtained by this way for G2-G4 is shown in Figure 4. The critical degree of dissociation $\alpha_{c}$ and critical geometric surface charge densities $\sigma_{\mathrm{c}}$, both corresponding to the onset of counterion binding, can be obtained from Figure 4 and are tabulated in Table 2.

Treiner et al. ${ }^{25}$ studied the degree of $\mathrm{Na}^{+}$binding to mixed micelles of SDS (dodecyl sulfate) and $\mathrm{C}_{12} \mathrm{E}_{23}\left[\mathrm{CH}_{3}\left(\mathrm{CH}_{2}\right)_{11}-\right.$ $\left.\mathrm{O}\left(\mathrm{CH}_{2} \mathrm{CH}_{2} \mathrm{O}\right)_{23} \mathrm{H}\right]$ by potentiometric measurements using a sodium ion-selective electrode and found counterion binding only when the mole fraction of SDS $(Y)$ in the micelle exceeds 0.15 . The binding degree increases gradually with $Y$, reaching a limiting value $\beta=0.75-0.80$ when $Y>0.7$. The $Y$ value at the onset of counterion binding corresponds to a surface charge density of $0.037 \mathrm{C} / \mathrm{m}^{-2}$, in excellent agreement with our result.

The role of counterion binding may be evaluated by examining the effect of counterion size; ${ }^{12-14}$ in particular, bulky counterions, such as tetramethylammonium ion $\left(\mathrm{TMA}^{+}\right)$, bind poorly compared to $\mathrm{Na}^{+} .{ }^{17}$ The dependence of $\mathrm{p} K_{\mathrm{a}}$ on $\alpha$ for TMACl is shown in Figure 5 (along with data for $\mathrm{NaCl}$ ). While there is no dependence on counterion at low $\alpha(\alpha \leq 0.35$ for $\mathrm{G} 3$ or $\leq 0.2$ for G4), there is a large effect at high $\alpha$. A similar effect has been observed by other researchers. Strauss and Schlesinger ${ }^{17}$ reported that the $\mathrm{pH}$ of a series of $1-1$ hydrolyzed copolymers of maleic anhydride and alkyl vinyl ether increased more steeply beyond $\alpha=0.5$ in TMACl than in $\mathrm{NaCl}$.

One possible reason for the discrepancy may be the dielectric constant effect. For cascade polymers G3 and G4 at $\alpha>0.7$, in TMACl, we find potentials even higher than the theoretical values (see Figure 6). The dielectric constant of solvent in the vicinity of an ion must be lower than that far away from it because the orientation of solvent dipoles reduces their sensitiv- 


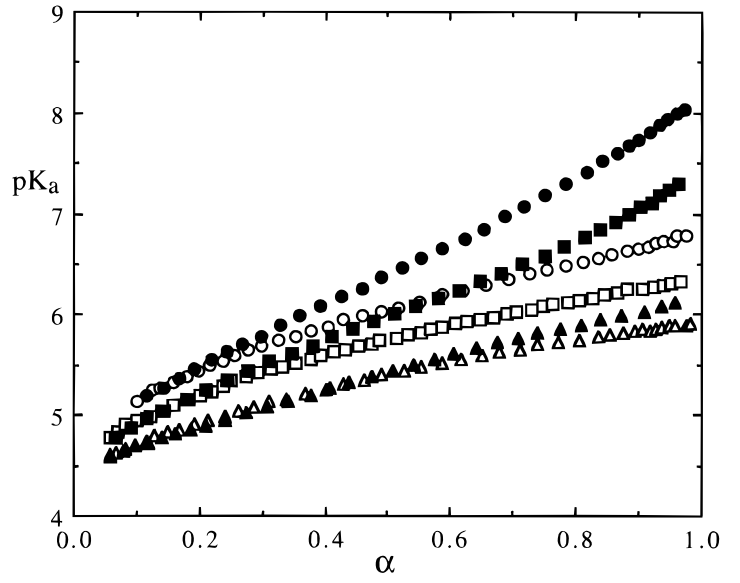

Figure 5. Relationship between $\mathrm{p} K_{\mathrm{a}}$ and $\alpha$ for cascade polymers in $0.10 \mathrm{M} \mathrm{NaCl}$ (open symbols) and TMACl (solid symbols): $\mathrm{G} 2(\triangle$, $\mathbf{\Delta}), \mathrm{G} 3(\square, \mathbf{\square})$, and $\mathrm{G} 4(\mathrm{O}, \boldsymbol{\bullet})$.

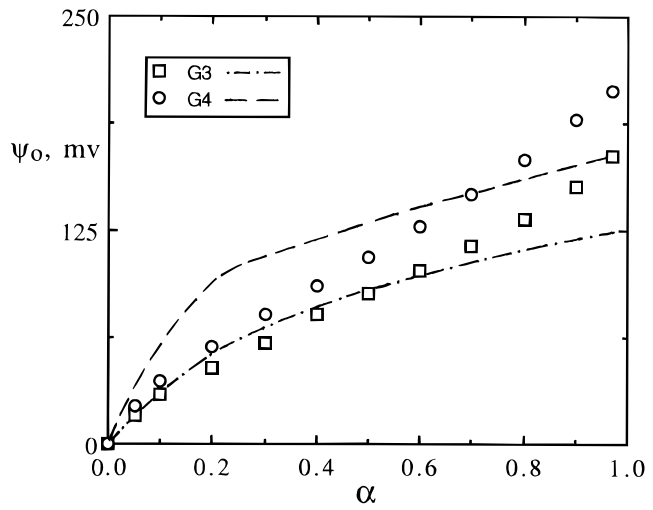

Figure 6. Surface potentials (absolute values) of cascade polymers in $0.10 \mathrm{M}$ TMACl: experimental (symbols), theoretical (broken lines). ity to the external field. Increase of the ion valence, i.e., its surface charge density, dramatically decreases the dielectric constant. According to Jayaram et al., ${ }^{26}$ the local dielectric constant at very short distance from the DNA surface is about 20. The surface charge density of high generation cascade polymers at high $\alpha$ (i.e., for $\mathrm{G} 4, \sigma_{(\alpha=0.7)}=0.34 \mathrm{C} / \mathrm{m}^{-2}$ ) is even higher than that of DNA $\left(0.32 \mathrm{C} / \mathrm{m}^{-2}\right)$, so the local dielectric constant $\epsilon_{1}$ may be much smaller than that of the bulk. Preliminary calculations using the $\mathrm{P}-\mathrm{B}$ equation show that the discrepancy between the experimental potentials in TMACl and the theoretical ones is partly reduced when smaller $\epsilon$ values are used. Since low $\epsilon$ favors interaction between oppositely charged particles, counterion binding must also be affected by a decrease in $\epsilon_{1}$. The overall effect of $\epsilon_{1}$ on the dissociation of cascade polymer should thus be considered from two aspects. In $\mathrm{NaCl}$, the lowering of the effective charge caused by strong $\mathrm{Na}^{+}$ binding dominates the dissociation, overriding the influence of $\epsilon_{1}$, leading to the low potentials relative to the theoretical vlaues. Since $\mathrm{TMA}^{+}$binds weakly compared to $\mathrm{Na}^{+}$, the net effect is a significant potential increase due to the decrease in $\epsilon_{1}$. A more detailed analysis of the effect of the local dielectric constant on the dissociation of cascade polymers is in progress.

Acknowledgment. This work was supported by the National Science Foundation (Grants PLD-DMR9311433 and GRNDMR9622609), as well as the US ARMY Office of Research (Grant GRN-DAAHO4-93-0048).

\section{References and Notes}

(1) Loeb, A. L.; Wiersema, P. H.; Overbeek, J. Th. G. The Electrical Double Layer around a Spherical Colloid Particle; MIT Press: Cambridge, MA, 1961.

(2) Ohshima, H.; Healy, T. W.; White, L. R. J. Colloid Interface Sci. 1981, 90, 17.

(3) Kawaguchi, S.; Yekta, A.; Winnik, A. J. Colloid Interface Sci. 1995, 176,362 .

(4) Hecht, J. L.; Honing, B.; Shin, Y. K.; Hubbell, W. L. J. Phys. Chem. 1995, 99, 7782 .

(5) Tanford, C.; Swan, S. A.; Shoree, W. S. J. Am. Chem. Soc. 1955 $77,6414$.

(6) Tanford, C.; Kirkwood, J. G. J. Am. Chem. Soc. 1957, 79, 5333.

(7) Tanford, C. J. Am. Chem. Soc. 1957, 79, 5340.

(8) Tanford, C.; Hauenstein, J. D. J. Am. Chem. Soc. 1956, 78, 5287.

(9) Hermans, J. J.; Overbeek, J. Th. G. Rec. Trav. Chim. Pays-Bas $1948,67,32$. 69.

(10) Katchalsky, A.; Shavit, N.; Eisenberg, H. J. Polym. Sci. 1954, 13,

(11) Dubin, P. L.; Strauss, U. P. J. Phys. Chem. 1970, 74, 2842.

(12) Kim, H. G.; Lee, J. H.; Lee, H. B.; Jhon, M. S. J. Colloid Interface Sci. 1993, 157, 82.

(13) Shimizu, T.; Kwak, J. C. T. J. Polym. Sci., Polym. Phys. Ed. 1985, $23,1139$.

(14) Kitano, T.; Kawaguchi, S.; Ito, K.; Minakata, A. Macromolecules 1987, 20, 1598.

(15) Tokiwa, F.; Ohki, K. J. Phys. Chem. 1966, 70, 3437.

(16) Zhang, H.; Dubin, P. L.; Kaplan, J. I. Langmuir 1991, 7, 2103.

(17) Strauss, U. P.; Schlesinger, M. S. J. Phys. Chem. 1978, 82, 571.

(18) Strauss, U. P.; Schlesinger, M. S. J. Phys. Chem. 1978, 82, 1627.

(19) Stenius, P.; Kronberg, B. In Science and Technology of Polymer Colloids. Surface Characterization of Latexes: Conductometry, Potentiometry, Electrophoresis, and Hydrodynamic Chromatography; Poehlein, G. W., Ottewill, R. H., Goodwin, J. W., Eds.; NATO ASI Series, Series E: Applied Sciences; Hijhoff: Boston, 1983; Vol. 68, 449.

(20) Newkome, G. R.; Moorefield, C. N. In Advances in Dendritic Macromolecules; Newkome, G. R., Ed.; JAI Press: Greenwich, CT, 1993; Chapter 1.

(21) Newkome, G. R.; Moorefield, C. N.; Vögtle, F. Dendritic MoleculesConcepts, Syntheses, Perspectives; VCH Publishers: Weinhion, Germany, 1996.

(22) Newkome, G. R.; Young, J. K.; Baker, G. R.; Potter, R. L.; Audoly, L.; Cooper, D.; Weis, C. D.; Morris, K.; Johnson, C. S., Jr. Macromolecules 1993, 26, 2394.

(23) Katchalsky, A.; Gillis, J. Rec. Trav. Chim. Pays-Bas 1949, 68, 879.

(24) Arnold, A.; Overbeek, J. Th. G. Rec. Trav. Chim. Pays-Bas 1950, 69, 192.

(25) Treiner, C.; Khodja, A. A.; Fromon, M. J. Colloid Interface Sci. 1989, 128,416

(26) Jayaram, B.; Swaminathan, S.; Beveridge, D. L.; Sharp, K.; Honig, B. Macromolecules 1990, 23, 3156. 